\title{
Effects of Increased Resistance to Umbilical Blood Flow on Fetal Hemodynamic Changes Induced by Maternal Oxygen Administration: A Doppler Velocimetric Study on the Sheep
}

\author{
SVEN-ERIK SONESSON, JEAN-CLAUDE FOURON, GEORGES TEYSSIER, AND PHILIPPE BONNIN \\ The Fetal Cardiology Unit, Pediatric Cardiology Service, Department of Pediatrics, St. Justine Hospital, \\ University of Montreal, Quebec, Canada
}

\begin{abstract}
A fetal lamb model was used to investigate whether the effects of maternal $\mathrm{O}_{2}$ administration on fetal blood gases and hemodynamics were modified when the fetoplacental circulation was compromised by stepwise compression of both umbilical veins. At basal state, $\mathbf{O}_{2}$ administration increased $\mathrm{O}_{2}$ saturation $\left(\mathrm{SaO}_{2}\right)$ and the pulsatility index (PI) of the carotid artery Doppler wave form $(p<0.01)$. The first compression decreased left ventricular output $(-21 \pm 16 \%$, mean $\pm 1 \mathrm{SD}, p<0.01)$ and umbilical mean velocity $(-22 \pm 28 \%, p<0.01)$ but did not modify carotid $\mathrm{pH}, \mathrm{SaO}_{2}$, or the PI in any of the arteries studied. At this level of compression, $\mathrm{O}_{2}$ administration increased carotid $\mathrm{SaO}_{2}(p<0.01)$ but did not affect carotid PI. After a second compression, left ventricular output and umbilical mean velocity were even more reduced $[-39 \pm 21 \%$ ( $p<$ $0.01)$ and $-53 \pm 23 \%(p<0.01)$, respectively]. With this compression, carotid $\mathrm{pH}, \mathrm{SaO}_{2}$, and PI decreased, whereas umbilical and descending aorta PI increased. $\mathrm{O}_{2}$ administration at this level of compression increased carotid $\mathrm{SaO}_{2}$ $(p<0.01)$ but did not modify carotid PI. Throughout the three stages of the experiment, $\mathrm{O}_{2}$ administration did not affect umbilical PI, descending aorta PI, or umbilical mean velocity. A good linear relationship $(r=0.77, p<0.001)$ was demonstrated between left ventricular $\mathrm{O}_{2}$ delivery and carotid PI. Thus, at basal state, $\mathrm{O}_{2}$ administration induced velocity changes compatible with an increase in cerebral vascular resistance. With an increase in umbilical vein resistance, this response was no longer demonstrated, even at a level of vein compression not significantly affecting carotid, umbilical, or descending aorta PI. These results support future use of fetal Doppler velocimetry during maternal hyperoxygenation as a method to evaluate fetal $\mathrm{O}_{2}$ reserve and fetoplacental hemodynamic function. (Pediatr Res 34: 796-800, 1993)
\end{abstract}

\section{Abbreviations}

$\mathrm{SaO}_{2}$, oxygen saturation

PI, pulsatility index

$\mathrm{Vm}$, temporal mean peak velocity

Received April 12, 1993; accepted July 13, 1993.

Correspondence and reprint requests: Dr. Jean-Claude Fouron, Division of Cardiology, St. Justine Hospital, 3175 Ch Cote Ste-Catherine, Montreal, Quebec H3T 1C5, Canada.

Supported by grants from the Medical Research Council of Canada, (MA9722). S.-E.S. was supported by a Research Fellowship of the Department of Pediatrics, University of Montreal, and by the Swedish Institute, the Swedish Medical Research Council, the Swedish Society of Medicine, and the Karolinska Institute.
Doppler ultrasonographic recordings of fetal and placental arterial blood velocity wave forms have been used to identify fetal compromise in high-risk pregnancies $(1,2)$. Experimental studies do, however, suggest that umbilical artery velocity wave form analysis is not sensitive enough to detect mild to moderate fetoplacental hemodynamic disturbances $(3,4)$. A redistribution of fetal blood flow to maintain cerebral $\mathrm{O}_{2}$ delivery and consumption during hypoxemia and hypoxia has been demonstrated in animal models (5-9). Findings made with the Doppler ultrasonographic technique indicate a similar redistribution of blood flow secondary to chronic hypoxemia in the growth-retarded human fetus (10). Despite these findings, the velocity wave form of the internal carotid artery has not been found reliable as an indicator of fetal well-being in intrauterine growth retardation (11). The hemodynamic response to maternal $\mathrm{O}_{2}$ administration has, however, been suggested as a possible predictor of outcome in the growth-retarded fetus (12). Thus, arterial velocity changes compatible with a normalization of blood flow redistribution indicated positive outcome, whereas no response was a marker of imminent fetal distress. However, fetal blood gases and $\mathrm{O}_{2}$ availability were not analyzed and it was not established whether there were differences in placental transfer of $\mathrm{O}_{2}$ between the fetuses who responded and those who did not respond.

The present study was performed to investigate by Doppler ultrasonography how the normal effects of maternal $\mathrm{O}_{2}$ administration on fetal blood gases and fetoplacental hemodynamics were modified when the umbilical circulation was compromised by a stepwise increase of resistance to placental flow.

\section{MATERIALS AND METHODS}

Eight near-term fetal lambs with a weight of $3.7 \pm 1.0 \mathrm{~kg}$ (mean $\pm 1 \mathrm{SD}$ ) and three controls weighing $3.1 \pm 0.1 \mathrm{~kg}$ were exteriorized and studied in acute experiments. The surgical procedure has previously been described (13). Maternal anesthesia was performed with alternating i.v. injections of ketamine hydrochloride $(3 \mathrm{mg} / \mathrm{kg})$ and sodium pentobarbital $(2 \mathrm{mg} / \mathrm{kg})$ every 20 to $40 \mathrm{~min}$. After exteriorization of one hind limb, an endhole catheter was introduced into the abdominal aorta via a femoral artery for determinations of arterial pressure and blood gases. The fetus was fully exteriorized and placed on the abdomen of the ewe, close to the incision, keeping almost all the umbilical cord within the temporarily closed uterine cavity. Fetal breathing was prevented by immediately putting the head into a surgical glove filled with saline solution. One common carotid artery was cannulated with an i.v. catheter ( $11 / 4 \mathrm{~mm}$ inner diameter) without obstruction of the vessel to obtain blood gases. Temperature was maintained by a radiant heater.

After approximately $30 \mathrm{~min}$ of stabilization, arterial blood gases, pressure, and velocities were recorded; thereafter, the ewe 
was administered $100 \% \mathrm{O}_{2}$ by face mask for at least $10 \mathrm{~min}$ before the same measurements were repeated during $\mathrm{O}_{2}$ administration. The $\mathrm{O}_{2}$ supplementation was discontinued and a third set of recordings were performed more than $5 \mathrm{~min}$ after stopping. These data were classified as basal state. Subsequently, a Goldblatt clamp was positioned around the umbilical veins and, during continuous recording of the umbilical artery velocity, compressed to a level at which the diastolic velocity was reduced by $50 \%$. Starting $10 \mathrm{~min}$ later, measurements described as basal state before, during, and after $\mathrm{O}_{2}$ administration were repeated. The compression of the umbilical veins was thereafter further increased, as just described, and the sequence of measurements repeated for a second time at this new level of resistance to umbilical flow. The whole procedure lasted approximately $3 \mathrm{~h}$. The controls followed the same procedure during the same period of time but the compression of the umbilical veins was omitted. Guidelines for the care and use of animals approved by the St. Justine Research Center were followed.

$\mathrm{Hb}$ level and arterial blood gas status were determined with an ABL 30 blood gas analyzer and an OSM 2 hemoximeter (Radiometer, Copenhagen, Denmark). Arterial pressure was recorded with a Cambridge recorder (Quinton Instruments, Montreal, Canada). Systolic and end-diastolic pressures were measured on approximately 20 wave forms, and mean pressure was calculated as the end-diastolic pressure plus one third of the systolic-diastolic difference.

Arterial velocities were measured with a range-gated Doppler system duplexed with a real-time mechanical sector scan (Sonos 100 or 500 , Hewlett-Packard Co., Palo Alto, CA). A $7.5-\mathrm{MHz}$ transducer was used to study the umbilical and common carotid arteries, and a $3.5-$ or $5.0-\mathrm{MHz}$ transducer was used to investigate the aorta. The high-pass filter was set at $100 \mathrm{~Hz}$. Guided by the two-dimensional image, Doppler audio signal and Doppler spectral-image recordings were made from the intraabdominal part of an umbilical artery by positioning the transducer just cephalad to the insertion of the cord, the noncannulated common carotid artery by placing the transducer over the artery on the extended neck and directing it toward the head, and the ascending and descending aorta with the transducer in the subxiphoid position. The angle of insonation was close to 0 in the umbilical artery and ascending aorta, approximately $20^{\circ}$ in the descending aorta, and almost $50^{\circ}$ in the common carotid artery. Calculations were made from the maximum envelope of the spectral analysis. Peak systolic (Vs), end-diastolic (Vd), and temporal mean (Vm) velocities and heart rate were averaged from three consecutive wave forms. PI was calculated using the formula PI $=(\mathrm{Vs}-\mathrm{Vd}) / \mathrm{Vm}$ (14). A parasternal view was used to measure the internal diameter (d) of the aorta. Left ventricular output (LVO) was calculated by the formula $\mathrm{LVO}=\pi \mathrm{d}^{2} \mathrm{Vm} / 4(15)$, and left ventricular $\mathrm{O}_{2}$ delivery as the product of $\mathrm{LVO}$ and carotid $\mathrm{O}_{2}$ content.

Statistical analyses were performed using two-way analysis of variance with Tukey's honest significant difference test, linear regression with analysis of variance, and the $F$ test. Multiple regressions with stepwise variable selection were made, using all observations, with the variables $\mathrm{pH}, \mathrm{SaO}_{2}, \mathrm{PcO}_{2}, \mathrm{Hb}$, heart rate, left ventricular stroke volume, and mean arterial pressure as independent variables and PI in the carotid artery as the dependent variable. $p$ values less than 0.05 were considered significant.

\section{RESULTS}

Physiologic measurements are found in Table 1 . The first compression decreased $\mathrm{SaO}_{2}$ in the descending aorta, whereas the second compression decreased not only descending aorta $\mathrm{SaO}_{2}$, but also carotid $\mathrm{SaO}_{2}$ and $\mathrm{O}_{2}$ content (Fig. 1c). Carotid pH, $\mathrm{PCO}_{2}$, and base excess remained unchanged until the second compression. Left ventricular output (Fig. $1 b$ ) and $\mathrm{O}_{2}$ delivery (Fig. 1d) decreased with both compression 1 and compression 2. PI in the carotid artery (Fig. $2 a$ ), descending aorta (Fig. $2 c$ ), and umbilical artery (Fig. 2d) were not changed by the first compression.
However, with the second compression, carotid PI decreased and descending aorta and umbilical PI increased. Both compression 1 and compression 2 decreased umbilical Vm $(65 \pm 22$ to $49 \pm$ 15 and $49 \pm 13$ to $31 \pm 10 \mathrm{~cm} / \mathrm{s}$, respectively, $p<0.01$ ).

$\mathrm{O}_{2}$ administration increased carotid and descending aorta $\mathrm{SaO}_{2}$ and carotid $\mathrm{O}_{2}$ content (Fig. 1c) at basal state and the two levels of venous compression. Left ventricular $\mathrm{O}_{2}$ delivery (Fig. Id) increased with $\mathrm{O}_{2}$ administration at basal state and the compression 1 level, but no effect was found at the compression 2 level. Carotid PI (Fig. 2a) increased at basal state but was not affected at the two levels of venous congestion. Left ventricular stroke volume (Fig. 1a), left ventricular output (Fig. $1 b$ ), descending aorta PI (Fig. 2c), umbilical PI (Fig. $2 d$ ), and umbilical Vm were not significantly affected at any period of $\mathrm{O}_{2}$ administration.

The three controls responded with an increase in carotid $\mathrm{SaO}_{2}$ and PI (Fig. $2 b$ ) at all three occasions of $\mathrm{O}_{2}$ administration, whereas the other blood gas variables did not tend to change during the experiment.

Multiple regression analysis selected $\mathrm{SaO}_{2}$, stroke volume, and heart rate as the best determinants of carotid PI $\left(r^{2}=0.83, p<\right.$ 0.001 ). A good linear correlation could accordingly be expected between left ventricular $\mathrm{O}_{2}$ delivery and carotid PI and was also demonstrated $\left(\mathrm{y}=0.65+0.41 \mathrm{x}, \mathrm{S}_{\mathrm{y} \cdot \mathrm{x}} 0.33, r=0.77, F=93.7, p\right.$ $<0.001$ )

\section{DISCUSSION}

Despite its limitations, this acute experimental model was preferred to the chronic preparation because of the need to obtain frequent and reproducible Doppler recordings from several fetal arteries during a limited time period. Great care was taken to maintain the fetal body temperature within physiologic limits and to keep the umbilical cord inside the uterine cavity and the uterus itself inside the maternal abdomen. The three control animals showed that, with these precautionary measures, stable and normal placental gas exchanges could be maintained during the entire period needed to complete the experimental protocol. Similarly, a reproducible response to maternal $\mathrm{O}_{2}$ administration could be obtained throughout the experiments in these control animals.

The present data indicate that umbilical vein compression reduces placental blood flow as suggested by a decrease in $\mathrm{Vm}$ of the umbilical artery and left ventricular output. These findings are in accordance with previous observations made with a dye dilution and radioactive microspheres technique $(16,17)$. This fall in ventricular output is most likely related to a decrease in venous return to the heart.

An increase of placental $\mathrm{O}_{2}$ transfer was demonstrated during maternal $\mathrm{O}_{2}$ administration, both at basal state and when the circulation was impaired. However, because of the marked reduction in left ventricular output created by the last umbilical vein compression, the rise in $\mathrm{O}_{2}$ content observed with $\mathrm{O}_{2}$ administration was not sufficient to change significantly the amount of $\mathrm{O}_{2}$ delivered by the left ventricle. This observation could be of significance in clinical situations such as severe intrauterine growth retardation with abnormal velocimetric indices in the umbilical artery.

Maternal $\mathrm{O}_{2}$ administration also increased the PI of the carotid artery at the basal level, but did not affect it at the two levels of umbilical vein compression. The PI and similar indices of the pulsatility of the velocity wave form are used to overcome one major problem with the Doppler technique, i.e. the dependence of the angle between the ultrasound beam and the direction of flow in the vessel. These indices, recorded from the umbilical artery, have been found to correlate with placental vascular resistance $(18,19)$ and placental microvascular pathology $(20)$ but have not been validated as markers of fetal cerebral vascular resistance or flow. A positive correlation has, however, been demonstrated between internal carotid PI and fetal $\mathrm{O}_{2}$ tension (21). Previous studies have shown an inverse relationship be- 
Table 1. Physiologic measurements before, during, and after maternal $\mathrm{O}_{2}$ administration at basal state and two levels of umbilical vein compression (compression 1 and 2)*

\begin{tabular}{|c|c|c|c|c|c|c|c|c|c|}
\hline & \multicolumn{3}{|c|}{ Basal state } & \multicolumn{3}{|c|}{ Compression 1} & \multicolumn{3}{|c|}{ Compression 2} \\
\hline & Before & During & After & Before & During & After & Before & During & After \\
\hline \multicolumn{10}{|l|}{ Carotid artery } \\
\hline $\mathrm{pH}$ & $\begin{array}{c}7.35 \\
(0.03)\end{array}$ & $\begin{array}{c}7.33 \\
0.03\end{array}$ & $\begin{array}{c}7.37 \\
(0.02)\end{array}$ & $\begin{array}{c}7.36 \\
(0.03)\end{array}$ & $\begin{array}{c}7.33 \\
(0.04)\end{array}$ & $\begin{array}{c}7.35 \\
(0.04)\end{array}$ & $\begin{array}{c}7.29 \dagger \\
0.05\end{array}$ & $\begin{array}{r}7.23 \ddagger \\
(0.08)\end{array}$ & $\begin{array}{c}7.17 \\
(0.211\end{array}$ \\
\hline $\mathrm{PCO}_{2}(\mathrm{kPa})$ & $\begin{array}{c}5.4 \\
(0.38)\end{array}$ & $\begin{array}{c}5.8 \\
(0.40)\end{array}$ & $\begin{array}{c}5.1 \\
(0.35)\end{array}$ & $\begin{array}{c}5.2 \\
(0.43)\end{array}$ & $\begin{array}{c}5.7 \\
(0.66)\end{array}$ & $\begin{array}{c}5.4 \\
(0.59)\end{array}$ & $\begin{array}{c}6.2 \\
(1.2)\end{array}$ & $\begin{array}{c}7.1 \\
(1.9)\end{array}$ & $\begin{array}{c}9.0 \S \\
(5.6)\end{array}$ \\
\hline $\mathrm{Po}_{2}(\mathrm{kPa})$ & $\begin{array}{c}2.8 \\
(0.58)\end{array}$ & $\begin{array}{c}4.0 \S \\
(0.58)\end{array}$ & $\begin{array}{c}2.7 \S \\
(0.38)\end{array}$ & $\begin{array}{c}2.6 \\
(0.48)\end{array}$ & $\begin{array}{c}3.5 \S \\
(0.58)\end{array}$ & $\begin{array}{c}2.5 \S \\
(0.40)\end{array}$ & $\begin{array}{l}2.4 \\
(0.38)\end{array}$ & $\begin{array}{c}3.0 \S \\
(0.90)\end{array}$ & $\begin{array}{c}2.4 \S \\
(0.63)\end{array}$ \\
\hline $\mathrm{SaO}_{2}(\%)$ & $\begin{array}{c}55.4 \\
(10.8)\end{array}$ & $\begin{array}{l}77.2 \S \\
(5.8)\end{array}$ & $\begin{array}{l}54.9 \S \\
(7.4)\end{array}$ & $\begin{array}{c}50.5 \\
(11.1)\end{array}$ & $\begin{array}{c}68.1 \S \\
(9.6)\end{array}$ & $\begin{array}{r}50.4 \S \\
(11.9)\end{array}$ & $\begin{array}{c}42.3 \| \\
(10.6)\end{array}$ & $\begin{array}{c}50.1 \S \\
(15.6)\end{array}$ & $\begin{array}{r}38.5 \S \\
(16.8)\end{array}$ \\
\hline $\mathrm{BE}(\mathrm{mmol} / \mathrm{L})$ & $\begin{array}{c}-2.8 \\
(1.7)\end{array}$ & $\begin{array}{c}-2.9 \\
(1.5)\end{array}$ & $\begin{array}{c}-2.6 \\
(1.3)\end{array}$ & $\begin{array}{c}-3.0 \\
(1.5)\end{array}$ & $\begin{array}{c}-3.3 \\
(2.6)\end{array}$ & $\begin{array}{c}-2.9 \\
(2.1)\end{array}$ & $\begin{array}{c}-4.2 \\
(1.9)\end{array}$ & $\begin{array}{c}-5.5 \\
(2.5)\end{array}$ & $\begin{array}{r}-7.9 \ddagger \\
(5.0)\end{array}$ \\
\hline $\mathrm{Hb}(\mathrm{g} / 100 \mathrm{~mL})$ & $\begin{array}{l}13.2 \\
(1.6)\end{array}$ & $\begin{array}{l}12.2 \S \\
(1.0)\end{array}$ & $\begin{array}{l}12.3 \\
(1.2)\end{array}$ & $\begin{array}{l}12.7 \\
(1.6)\end{array}$ & $\begin{array}{l}12.6 \\
(1.3)\end{array}$ & $\begin{array}{l}12.9 \\
(1.7)\end{array}$ & $\begin{array}{l}13.2 \\
(2.2)\end{array}$ & $\begin{array}{l}13.4 \\
(1.4)\end{array}$ & $\begin{array}{l}13.9 \\
(1.1)\end{array}$ \\
\hline HR (bpm) & $\begin{array}{l}221 \\
(24)\end{array}$ & $\begin{array}{l}211 \\
(28)\end{array}$ & $\begin{array}{l}209 \\
(38)\end{array}$ & $\begin{array}{l}188 \\
(52)\end{array}$ & $\begin{array}{l}181 \\
(29)\end{array}$ & $\begin{array}{c}210 \ddagger \\
(34)\end{array}$ & $\begin{array}{l}167 \| \\
(24)\end{array}$ & $\begin{array}{l}187 \\
(40)\end{array}$ & $\begin{array}{l}178 \\
(38)\end{array}$ \\
\hline \multicolumn{10}{|l|}{ Descending aorta } \\
\hline $\mathrm{PO}_{2}(\mathrm{kPa})$ & $\begin{array}{l}2.5 \\
(0.40)\end{array}$ & $\begin{array}{c}3.9 \S \\
(0.42)\end{array}$ & $\begin{array}{c}2.6 \S \\
(0.42)\end{array}$ & $\begin{array}{c}2.3 \| \\
(0.54)\end{array}$ & $\begin{array}{c}3.2 \S \\
(0.58)\end{array}$ & $\begin{array}{c}2.2 \S \\
(0.37)\end{array}$ & $\begin{array}{c}2.1 \\
(0.39)\end{array}$ & $\begin{array}{c}2.7 \S \\
(0.83)\end{array}$ & $\begin{array}{c}2.1 \S \\
(0.63)\end{array}$ \\
\hline $\mathrm{SaO}_{2}(\%)$ & $\begin{array}{c}48.4 \\
(11.3)\end{array}$ & $\begin{array}{l}73.48 \\
(6.4)\end{array}$ & $\begin{array}{c}49.1 \S \\
(8.2)\end{array}$ & $\begin{array}{c}41.8 \| \\
(10.9)\end{array}$ & $\begin{array}{c}61.68 \\
(9.2)\end{array}$ & $\begin{array}{r}42.3 \S \\
(10.5)\end{array}$ & $\begin{array}{r}36.5 \dagger \\
(11.5)\end{array}$ & $\begin{array}{c}43.2 \S \\
(14.1)\end{array}$ & $\begin{array}{c}33.2 \S \\
(14.3)\end{array}$ \\
\hline $\mathrm{MAP}(\mathrm{mm} \mathrm{Hg})$ & $\begin{array}{l}65 \\
(7)\end{array}$ & $\begin{array}{l}60 \ddagger \\
(5)\end{array}$ & $\begin{array}{l}60 \\
(7)\end{array}$ & $\begin{array}{l}61 \\
(8)\end{array}$ & $\begin{array}{c}62 \\
(11)\end{array}$ & $\begin{array}{c}62 \\
(12)\end{array}$ & $\begin{array}{l}63 \\
(9)\end{array}$ & $\begin{array}{l}62 \\
(6)\end{array}$ & $\begin{array}{l}62 \\
(5)\end{array}$ \\
\hline
\end{tabular}

* Values are mean (1 SD). BE, base excess; HR, heart rate; MAP, mean arterial pressure. Significant changes from previous recording are denoted by symbols.

$+p<0.05$ (effect related to compression).

$¥ p<0.05$ (effect related to $\mathrm{O}_{2}$ ).

$\S p<0.01$ (effect related to $\mathrm{O}_{2}$ ).

$\| p<0.01$ (effect related to compression).
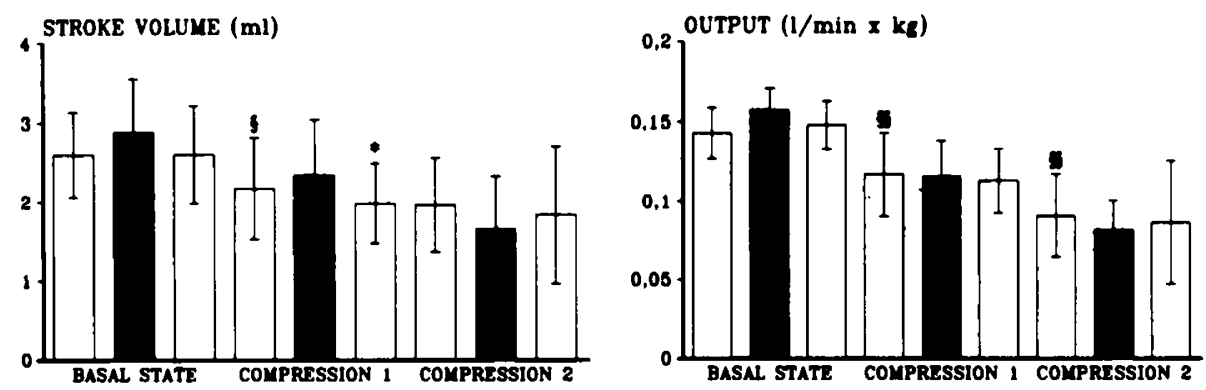

(a)

(b)
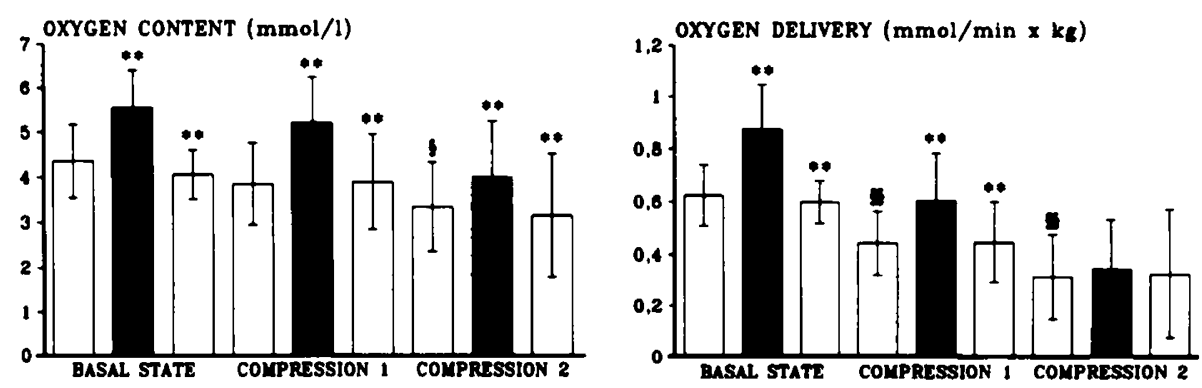

(c)

(d)

Fig. 1. Left ventricular stroke volume, output, $\mathrm{O}_{2}$ content, and $\mathrm{O}_{2}$ delivery at basal state and two levels of umbilical compression. The three bars at each level are results obtained before, during (filled), and after maternal oxygen administration (mean \pm 1 SD). Significant changes from previous recording are denoted as ${ }^{*}, \S(p<0.05)$ and ${ }^{* *}, \S \S(p<0.01)$. Different symbols are used to distinguish between the effects related to $\mathrm{O}_{2}\left({ }^{*}\right)$ and compression (\$).

tween arterial $\mathrm{O}_{2}$ content and fetal cerebral blood flow $(6,8)$. The increase in carotid PI observed in our animals during maternal $\mathrm{O}_{2}$ administration at basal state can therefore be interpreted as an increase in cerebral vascular resistance. The first compression did not modify carotid blood gases or the PI in any of the arteries studied. Thus, the carotid PI response to $\mathrm{O}_{2}$ administration was abolished even at a level of fetoplacental hemodynamic disturbance that was not detected in umbilical, descending aorta, or carotid PI.

The data available in this study are not sufficient to explain 

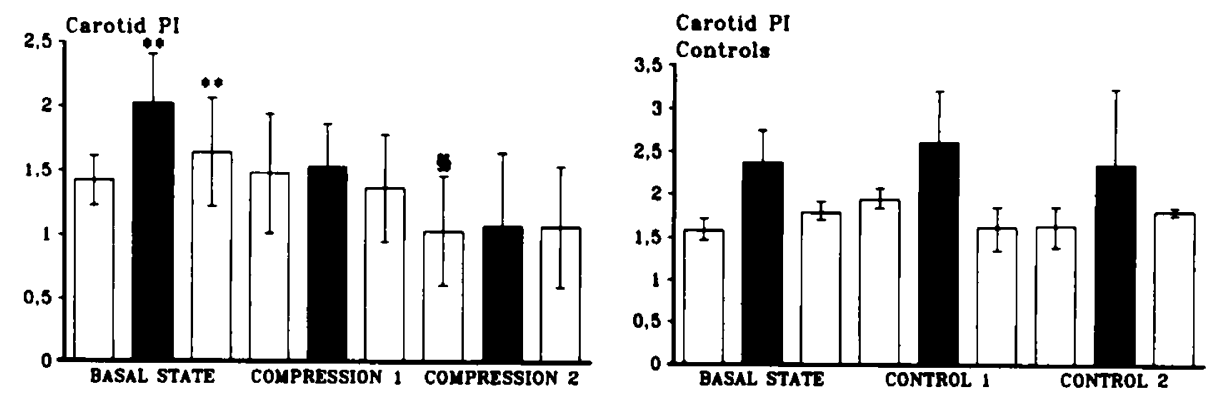

(•)

(b) Mean (Range)
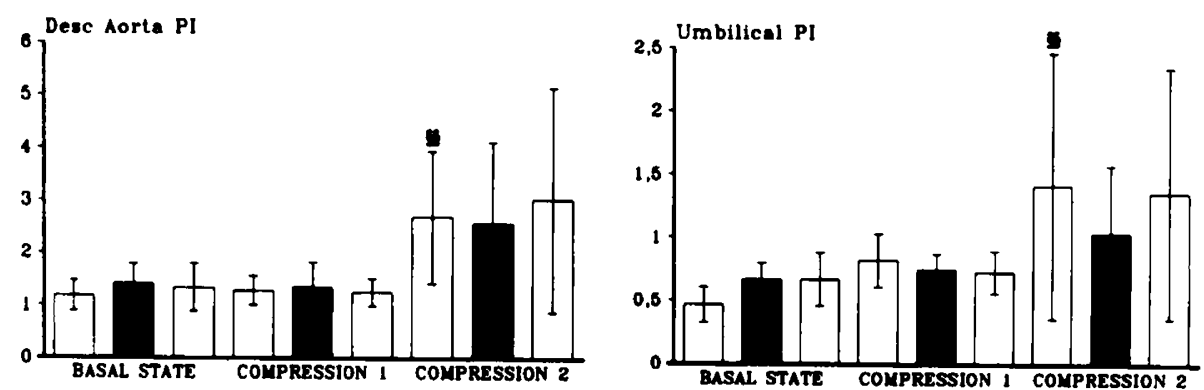

(c)

(d)

Fig. 2. PI in the carotid artery, descending aorta, and umbilical artery at basal state and two levels of umbilical compression. Bars and symbols are presented as in Figure 1 . The controls $(n=3)$, presented with mean and range, were not statistically validated.

the mechanism responsible for this finding. One possible explanation may be that when $\mathrm{O}_{2}$ delivery is decreased, the brain, in addition to vasodilatation, is using an increased $\mathrm{O}_{2}$ extraction as another compensatory mechanism. The administration of $\mathrm{O}_{2}$ during impaired umbilical circulation could then only influence $\mathrm{O}_{2}$ oxygen extraction, but the amount of $\mathrm{O}_{2}$ delivered would not be sufficient to cause any significant change in vascular resistance. In accordance with this speculation, a decrease in descending aorta $\mathrm{SaO}_{2}$, despite an unchanged carotid $\mathrm{SaO}_{2}$, occurred when the umbilical veins were compressed the first time. This speculation is also in agreement with recent observations where, using the microsphere technique, an increase in fetal $\mathrm{O}_{2}$ extraction was demonstrated when umbilical blood was reduced by $25 \%$, whereas a $75 \%$ reduction was needed to demonstrate a significant increase in brain blood flow (17). Obviously, this chain of events could be different in cases of fetal hypoxemia without a fall in cardiac output. Nevertheless, a good linear relationship was demonstrated between $\mathrm{PI}$ and $\mathrm{O}_{2}$ delivery from the left ventricle. Furthermore, stroke volume, $\mathrm{SaO}_{2}$, and heart rate were found to be the best predictors of carotid PI in a multiple linear model.

In summary, in the presence of a normal umbilical circulation, the fetal carotid artery demonstrates velocity wave form changes with maternal $\mathrm{O}_{2}$ administration that are compatible with an increase in cerebral vascular resistance. With a disturbance in fetoplacental hemodynamics, not detected with commonly used indices of fetal well-being, this response was not demonstrated. In this context, $\mathrm{O}_{2}$ supplementation could be regarded as a test for estimation of fetal $\mathrm{O}_{2}$ reserve with the possible potential of identifying hemodynamic disturbances in fetuses with normal Doppler indices of well-being. It must be emphasized that an absence of increase in fetal carotid PI during $\mathrm{O}_{2}$ administration only means impairment in the availability of $\mathrm{O}_{2}$ to the brain, not necessarily tissue hypoxia. Finally, with marked increase in resistance to umbilical blood flow, no benefit seems to be gained from maternal $\mathrm{O}_{2}$ therapy. These experimental results support further clinical investigation on the use of Doppler velocimetry during maternal hyperoxygenation on human fetuses with compromised fetoplacental hemodynamics.

\section{REFERENCES}

1. Rochelson BL, Schulman H, Fleischer A, Farmakides G, Bracero L, Ducey L Winter D, Penny B 1987 The clinical significance of Doppler umbilical artery velocimetry in the small for gestational age fetus. Am J Obstet Gynecol 156:1223-1226

2. Trudinger BJ, Giles WB, Cook CM 1985 Flow velocity waveforms in the maternal uteroplacental and fetal umbilical placental circulation. Am J Obstet Gynecol 152:155-163

3. Schmidt KG, di Tommaso M, Silverman NH, Rudolph AM 1991 Evaluation of changes in umbilical blood flow in the fetal lamb by Doppler waveform analysis. Am J Obstet Gynecol 164:1118-1126

4. Copel JA, Schlafer D, Wentworth R, Belanger K, Kreitzer L, Hobbins JC, Nathanielsz PW 1990 Does the umbilical artery systolic/diastolic ratio reflect flow or acidosis? Am J Obstet Gynecol 163:751-756

5. Sheldon RE, Peeters LLH, Jones Jr MD, Makowski EL, Meschia G 1979 Redistribution of cardiac output and oxygen delivery in the hypoxemic fetal lamb. Am J Obstet Gynecol 135:1071-1078

6. Peeters LLH, Sheldon RE, Jones Jr MD, Makowski EL, Meschia G 1979 Blood flow to fetal organs as a function of arterial oxygen content. Am J Obstet Gynecol 135:637-646

7. Ashwal S, Majcher JS, Vain N, Longo LD 1980 Patterns of fetal lamb regional cerebral blood flow during and after prolonged hypoxia. Pediatr Res 14:1104-1110

8. Ashwal S, Dale PS, Longo LD 1984 Regional cerebral blood flow. Studies in the fetal lamb during hypoxia, hypercapnia, acidosis, and hypotension. Pediatr Res 18:1309-1316

9. Block BSB, Llanos AJ, Creasy RK 1984 Response of the growth-retarded fetus to hypoxemia. Am J Obstet Gynecol 148:878-88

10. Wladimiroff JW, Tonge HM, Stewart PA 1986 Doppler ultrasound assessment of cerebral blood flow in the human fetus. Br J Obstet Gynaecol 93:471-475

11. Wladimiroff JW, Noordam MJ, van den Wijngaard JAGW, Hop WJC 1988 Fetal internal carotid and umbilical artery blood flow velocity waveforms as a measure of fetal well-being in intrauterine growth retardation. Pediatr Res 24:609-612

12. Arduini D, Rizzo G, Romanini C, Mancuso S 1989 Hemodynamic changes in growth retarded fetuses during maternal oxygen administration as predictors of fetal outcome. J Ultrasound Med 8:193-196

13. Fouron JC, Teyssier G, Maroto E, Lessard M, Marquette G 1991 Diastolic circulatory dynamics in the presence of elevated placental resistance and retrograde diastolic flow in the umbilical artery. A Doppler echocardiographic study in lambs. Am J Obstet Gynecol 164:195-203

14. Gosling RG, King DH 1975 Ultrasonic angiology. In: Harcus AW, Adamson L (eds) Arteries and Veins. Churchill Livingstone, Edinburgh, UK, pp $61-$ 98

15. Alverson DC, Eldridge MW, Dillon T, Yabeck SM, Berman W 1982 Noninvasive pulsed Doppler determination of cardiac output in neonates and children. J Pediatr 101:46-50

16. Goodwin JW, Mahon WA, Reid DW 1968 Effect of graded reduction of umbilical blood flow on right and left ventricular outputs in the fetal lamb. Circ Res 22:595-603

17. Iwamoto HS, Stucky E, Roman CM 1991 Effect of graded umbilical cord compression in fetal sheep at 0.6-0.7 gestation. Am J Physiol 261:H1268H1274

18. Trudinger BJ, Stevens D, Connelly A, Hales JR, Alexander G, Bradley L, 
Fawcett A, Thompson RS 1987 Umbilical artery flow velocity waveforms and placental resistance: the effect of embolization of the umbilical circulation. Am J Obstet Gynecol 157:1443-1448

19. Morrow RJ, Adamson SL, Bull SB, Ritchie JWK 1989 Effect of placental embolization on the umbilical arterial velocity waveform in fetal sheep. Am J Obstet Gynecol 161:1055-1060
20. Giles WB, Trudinger BJ, Baird PJ 1985 Fetal umbilical artery flow velocity waveform and placental resistance: pathological correlation. $\mathrm{Br} \mathrm{J}$ Obstet Gynaecol 92:31-38

21. Simonazzi E, Wladimiroff JW, van Eyck J 1989 Flow velocity waveforms in the fetal internal carotid artery relative to fetal blood gas and acid-base measurements in normal pregnancy. Early Hum Dev 19:111-115 